\title{
Neonatal Cerebrospinal Fluid, Bacterial Analysis as Seen at the University of Port Harcourt Teaching Hospital: A Five-Year Review
}

\author{
Yaguo Ide Lucy Eberechukwu ${ }^{*}$, Awopeju Abimbola Temitayo ${ }^{2}$ \\ ${ }^{1}$ Department of Paediatrics and Child Health, University of Port Harcourt Teaching Hospital, \\ Port Harcourt, Nigeria \\ ${ }^{2}$ Department of Medical Microbiology and Parasitology, University of Port Harcourt Teaching Hospital, \\ Port Harcourt, Nigeria \\ Email: *lucyaguolucy@gmail.com
}

Received 17 December 2015; accepted 4 April 2016; published 7 April 2016

Copyright (C) 2016 by authors and Scientific Research Publishing Inc.

This work is licensed under the Creative Commons Attribution International License (CC BY). http://creativecommons.org/licenses/by/4.0/

c) (i) Open Access

\section{Abstract}

Background: Cerebrospinal fluid analysis is a very important tool in the diagnosis of bacterial meningitis in the new born. Bacterial meningitis is a potent cause of morbidity and mortality in the neonatal age group, with a very high incidence of neurological complications. Aim: To identify the bacterial pathogens isolated from the cerebrospinal fluids of neonates at the University of Port Harcourt Teaching Hospital (UPTH) and their sensitivity patterns. This will assist the neonatologist in the choice of empirical antibiotic treatment. Study Design: Retrospective, descriptive, cross sectional study. Place and duration of study: University of Port Harcourt Teaching Hospital, from 1 January 2009 to 31 December 2014. Methods: Records of bacterial analysis of cerebrospinal fluid from neonates seen at the special care baby unit of the University of Port Harcourt Teaching Hospital with clinical suspicion of meningitis between 1 January 2009 and 31 December 2014 were retrieved from the microbiology record book. Data on patients age, sex, appearance of Cerebrospinal fluid, cell count, microscopy/gram stain, culture and antibiotic sensitivity were retrieved from laboratory record books and entered into a Microsoft ${ }^{\circledR}$ excel spread sheet and analysed using SPSS version 20.0. Results: One hundred and thirteen neonates: $70(61.95 \%)$ of these patients were male while $43(38.05 \%)$ were females. Only $1(0.89 \%)$ was positive for culture yielding a growth of Escherichia coli which was sensitive to Imipenem, moderately sensitive to Ampicillin, Gentamicin, ceftazidime, cefuroxime, ciprofloxacin and Amoxicillin-clavulanic acid. It was resistant to cefotaxime. $112(99.11 \%)$ of the neonates had presumed neonatal meningitis while only 1

\footnotetext{
${ }^{*}$ Corresponding author.
}

How to cite this paper: Eberechukwu, Y.I.L. and Temitayo, A.A. (2016) Neonatal Cerebrospinal Fluid, Bacterial Analysis as Seen at the University of Port Harcourt Teaching Hospital: A Five-Year Review. Advances in Microbiology, 6, $247-250$. 
$(0.89 \%)$ had proven neonatal meningitis. Conclusions: There is a low yield of organisms in cerebrospinal fluid of neonates at the University of Port Harcourt Teaching Hospital.

Keywords

Cerebrospinal Fluid, Neonates, Bacteria, Culture, Meningitis, Sensitivity Pattern

\section{Introduction}

Acute bacterial meningitis is a life threatening infection [1]. It is a global public health problem with an annual incidence of $1-2$ cases [2], an important cause of morbidity in Africa [3]. Mortality from neonatal meningitis has remained high $(60 \%)$ in most reports, despite appropriate antibiotic therapy and highly skilled new born intensive care units [4].

Incidence of neonatal bacterial meningitis was reported as $1.3 \%$ in a district hospital in Kenya [3]. In Nigeria it was reported to range from $1.6 \%$ in Ilesha [5] western Nigeria to $6 \%$ in Kano Northern Nigeria [6]. Mortality rate from meningitis has remained high $(15 \%$ to $60 \%)$ world-wide leaving its survivors with significant neurologic and developmental complications [7].

Neonatal mortality in Nigeria is high (37\%) and infections are responsible for $22 \%$ of these deaths [8]. There are well documented reports in literature on the aetiology and treatment of bacterial meningitis in the Paediatric age group (neonates and older children) [9]. Haemophillus influenza, Streptococcus pneumoniae and Neisseria meningitides are organisms most frequently implicated in causation of bacterial meningitis in the older children while Group B Streptococcus, Gram negative Coliforms Escherichia coli and Listeria monocytogenes are organisms most frequently implicated in neonates [9]. Signs of infections like meningitis are usually nonspecific in the new born hence diagnosis of meningitis must be by lumbar puncture with subsequent analysis of the cerebrospinal fluid [10].

The third generation cephalosporins are currently the empirical drug of choice employed in treatment of neonatal bacterial meningitis generally and in Nigeria. There is the fear that prolonged use of the third generation cephalosporins may encourage the emergence of resistant organisms [11], hence there is a need to periodically review the pattern of organisms seen in cerebrospinal fluid of neonates in our environment and their antibiogram.

The aim of this study therefore was to retrospectively review the result of analysis of cerebrospinal fluid of neonates with clinical suspicion of meningitis reported in the microbiology report book of the Department of Medical microbiology and parasitology of the University of Port Harcourt Teaching Hospital over a five-year period of January 2009 to December 2014.

\section{Methodology}

The study was carried out at the University of Port Harcourt Teaching Hospital (UPTH) Rivers State, Nigeria. The teaching hospital apart from taking care of patients located in the state, also attends to referral cases from the entire South-south region of the country.

A retrospective analysis of 657 clinically suspected cases of meningitis, admitted during a 5 -year period from January 2009 to December 2014 was undertaken. Inclusion criteria were all clinically ill patients suspected of having meningitis that were in the neonatal age group. Exclusion criteria were every paediatric patient with clinical suspicion of meningitis who are above the neonatal period and neonatal patients with clinical suspicion of meningitis whose data are incompletely reported.

Data were retrieved from laboratory record books of the department of microbiology and parasitology and entered into a Microsoft ${ }^{\circledR}$ excel spreadsheet. Demographic data, clinical diagnoses, cerebrospinal fluid (CSF) appearance, WBC cell count, type of isolated organisms, and antibiotic susceptibility profile of organisms were collected. Data was analysed using Statistical package for social sciences version 20.0.

\section{Results}

During the period of this study, a total of 113 results of analysis of cerebrospinal fluid sample from neonates 
were reported. Forty three (38.05\%) were from female patients while $70(61.95 \%)$ were from males patients. Male and Female ratio is $1.6: 1$. Only $1(0.89 \%)$ of the samples from a day old female patient was positive for culture yielding a growth of Escherichia coli which was moderately sensitive to Ampicillin, Gentamicin, ceftazidime, cefuroxime, ciprofloxacin and Amoxicillin-clavulanic acid. It was resistant to cefotaxime but sensitive to Imip-enem.

\section{Age and Sex Distribution of Study Population}

\begin{tabular}{cccc}
\hline AGE IN DAYS & \multicolumn{2}{c}{ SEX } & TOTAL (\%) \\
\hline$\leq 1$ & M (\%) & F (\%) & $5(4.42)$ \\
$1-7$ & $3(2.65)$ & $2(1.77)$ & $33(29.20)$ \\
$>7-28$ & $24(21.23)$ & $9(7.96)$ & $75(66.37)$ \\
TOTAL & $43(38.05)$ & $32(28.32)$ & $113(100)$ \\
\hline
\end{tabular}

\section{Discussions}

In our study, there was a low culture positive rate of $0.89 \%$, this is much lower than the $6 \%$ culture positive rate reported from neonates in Aminu Kano teaching hospital in Northern Nigeria [6] 1.6\% among children aged 8 weeks to 14 years in Ilesha in the south western part of Nigeria [5] and 1.3\% reported among paediatric patients in a district hospital in Kenya [3]. However our culture positive rate of $0.89 \%$ is similar to $0.96 \%$ positive rate among neonates in Louis Ville as reported by Franco et al. [7]. The observed differences in reports from Ilesha and Kenya could be because those two studies were in older children while ours was among neonates. The observed difference between our study and that from Kano state, Nigeria could be because Kano state falls within the meningitis belt while Port Harcourt is not within this belt. This could account for the much higher culture positive rate in neonates in Kano (6\%) [6] than in Port Harcourt (0.89\%), Nigeria. Our report is comparable to $0.69 \%$ culture positive rate obtained among paediatric patients in Nnewi South east Nigeria [12] and 0.96 from neonates in Louis Ville [7] although the subjects in the study from Nnewi were not all neonates, but like our present study, both studies were done in the southern part of Nigeria which is outside the meningitis belt. However, this present report and that from Louis Ville [7] are both among neonates.

Several reasons have been advanced in literature as being responsible for a low culture positive rate in CSF and they include among others, intake of antibiotics before presentation for treatment at the hospital, depletion of delicate organisms like N. meningitides in the course of delay in transportation and testing of CSF sample, improper technique of lumber puncture, delay in transportation of specimen to the laboratory, non-availability of special media for specific pathogens in the emergency setting, autolysis enzymes in the CSF, fastidious nature of pathogens [13] [14]. These reasons are equally prevalent in our environment, as most parents that bring their children to the University of Port Harcourt Teaching Hospital for treatment would have started them on antibiotics bought from over the counter or gone to private clinics where different antibiotics would have been administered before referral.

Predominance of Escherichia coli isolated in this study is comparable to that obtained in the report from Kano state Nigeria where E. coli was the predominate organism among neonates [6] and the report of Enzenauer and Bass from the United States [15].

The high rate of sterile CSF (99.11\%) observed in this study is comparable to $96.7 \%$ observed by Nwadioha et al. from Kano state Nigeria. Prior use of antibiotics before presentation in hospital could have accounted for this as this is a common practise in Nigeria and other developing countries [6] [16].

The problem of sterile CSF results can readily be overcome by employing the use of newer methods of diagnoses that do not require the growth of live pathogens such as polymerase chain reaction and latex agglutination. E. coli isolated in this study was not very sensitive to the commonly used antibiotics in our hospital ampicillin, gentamicin, ceftazidime, cefuroxime, ciprofloxacin and amoxicillin-clavulanic acid this may have been from the problem of antibiotic misuse which is very common in this region [6].

One major limitation of this study was failure to subject the organisms to ceftriaxone which is a commonly used antibiotic for bacterial meningitis. It is recommended that the study be repeated in the light of this as this 
will contribute immensely to the management of neonates with suspected bacterial meningitis in this region.

\section{Conclusion}

Incidence of confirmed meningitis in neonates in Port Harcourt is low. Newer methods of diagnosis of meningitis should be employed. Restriction should be placed on purchase of antibiotics from over the counter.

\section{References}

[1] Harmony, P., Garges, M., Anthony, M., Michael, C., Brian, S., Kenneth, F., et al. (2006) Neonatal Meningitis: What Is the Correlation among CSF Cultures, Blood Cultures and CSF Parameters. Pediatrics, 117, 1094-1100. http://dx.doi.org/10.1542/peds.2005-1132

[2] Carlos, F., Lorena, L., Isabel, H. and Ignacio, S. (2008) Epidemiology and Outcomes of Bacterial Meningitis in Mexican Children: 10-Year Experience (1993-2003). International Journal of Infectious Diseases, 12, 380-386.

[3] Mwangi, I., Berkley, J., Lowe, B., Peshu, N., Marsh, K. and Newton, C.R. (2002) Acute Bacterial Meningitis in Children Admitted to a Rural Kenyan Hospital: Increasing Antibiotic Resistance and Outcome. Pediatric Infectious Disease Journal, 21, 1042-1048. http://dx.doi.org/10.1097/00006454-200211000-00013

[4] Robert, H.A., Haslam, J.R., Allen, M.M., Dorsen, D.L., Kanofsky, E.D. and Mellits, D.A.N. (1977) The Sequalae of Group B Haemolytic Streptococcal Meningitis in Early Infancy. American Journal of Diseases of Children, 131, 845849.

[5] Ogunlesi, T.A., Okeniyi, J.A.O. and Oyelaemi, O.A. (2005) Pyogenic Meningitis in Ilesa, Nigeria. Indian Journal of Pediatrics, 42, 1019-1023.

[6] Nwadioha, S.I., Onwuezube, I., Egesie, J.O., Kashibu, E. and Nwokedi, E.O.P. (2011) Bacterial Isolates from Cerebrospinal Fluid of Suspected Acute Meningitis in Nigerian Children. International Journal of Infectious Disease, 1, 8.

[7] Sofia, M.F., Victoria, E.C. and Billy, F.A. (1992) Long-Term Outcome of Neonatal Meningitis. The American Jewelry Design Council, 46, 567-571.

[8] (2015) Nigerian State Data Profiles-An Accountability Tool for Maternal Newborn and Child Health.

[9] Eric, T.B., Augustine, R.N.A. and Russell, W.S. (1983) Bacterial Meningitis in Older Neonates. American Journal of Diseases of Children, 137, 1052-1054.

[10] Theodoridou, M.N., et al. (2007) Meningitis Registry of Hospitalized Cases in Children: Epidemiological Patterns of Acute Bacterial Meningitis throughout a 32-Year Period. BMC Infectious Diseases, 7, 101. http://dx.doi.org/10.1186/1471-2334-7-101

[11] Fulginiti, V.A. (1983) Treatment of Meningitis in the Very Young Infant. American Journal of Diseases of Children, 137, 1043.

[12] Ugochukwu, E.F. (2006) Presentation and Outcome of Pyogenic Meningitis in Children: The Experience in Nnewi, Southeast Nigeria. Tropical Journal of Medicinal Research, 10, 22-25.

[13] Maleeha, A., Rubeena, H. and Tahir, M. (2006) Bacterial Meningitis: A Diagnostic Approach. Biomedica, $22,96-98$.

[14] Madhumita, P. and Gupta, N. (2011) Clinical and Bacteriological Spectrum of Community Acquired Bacterial Meningitis in Adults at Tertiary Care Hospital in Northen India. International Journal of Nutrition, Pharmacology, Neurological Diseases, 1, 194-200.

[15] Robert, W., Enzenauer, M.C., James, W. and Bass, M.C. (1983) Initial Antibiotic Treatment of Purulent Meningitis in Infants 1 to 2 Months of Age. American Journal of Diseases of Children, 137, 1055-1056.

[16] Modi, G.B., Patel, K.D., Soni, S.T., Patel, K.J., Mangukiya, J.D. and Jain, P.S. (2012) Bacteriological Profile of Pyogenic Meningitis in Tertiary Care Hospital, Ahmedabad. National Journal of Medical Research, 2, 313-317. 